\title{
HEREDOGRAMA X FORMAS GEOMÉTRICAS: interlocuções entre ciências e matemática na infância
}

\author{
HEREDOGR AM X GEOMETRIC FORMS: interlocations between science and mathematics on the childhood
}

\author{
José Carlos Pinto Leivas. ${ }^{1}$ \\ Ana Raquel Beckmann ${ }^{2}$ \\ Cristina da Silva dos Santos. ${ }^{3}$ \\ Rosemar de Fátima Vestena ${ }^{4}$
}

\begin{abstract}
RESUMO: O artigo apresenta um estudo das práticas pedagógicas realizadas em uma disciplina de um mestrado profissional em uma universidade privada do sul do Brasil. O objetivo foi analisar possíveis interlocuções entre as áreas do conhecimento Ciências da Natureza e Matemática, a partir do recurso didático heredograma. Ao desenvolver a disciplina de forma interdisciplinar, realizada com dois professores, atuando simultaneamente na sala de aula, a possibilidade de atingir tal objetivo foi uma construção coletiva, que propiciou inovação para o ensino. Pelas características do heredograma, foi possível envolver conteúdos das duas disicplinas, articulando as peças desse artefato. Nele, estão presentes as formas geométricas nas representações das constituições dos elos hereditários. O experimento foi realizado durante a disciplina ocorrida no primeiro semestre do ano de 2019, para mestrandos pedagogos. Os resultados mostraram ser viável desenvolver a disciplina de forma interdisciplinar, envolvendo dois profissionais de áreas distintas atuando conjuntamente, além de participantes que criaram atividades por meio de jogos que possibilitaram a interlocução de saberes dessas áreas.
\end{abstract}

Palavras-chaves: Formas geométricas. Heredogramas. Práticas pedagógicas..

ABSTRACT: The article presents a study of the pedagogical practices carried out in a professional master's degree course at a private university in southern Brazil. The objective was to analyze the possible interlocutions between the areas of knowledge Natural Sciences and Mathematics from the didactic resource heredogram. By developing the discipline in an interdisciplinary way, carried out with two teachers, acting simultaneously in the classroom, the possibility of achieving this goal is a collective construction that provides the new form of teaching. Due to the characteristics of the herodogram, it was possible to involve the contents of the two disciplines articulating the heredogram pieces. In it the geometric forms are present in the representations of the constitutions of the hereditary links. The experiment conducted in the construction of the discipline that took place in the first semester of 2019 for pedagogical master's students is justified. Results showed to be viable to develop the discipline in an interdisciplinary way, involving two

\footnotetext{
${ }^{1}$ Universidade Franciscana, Licenciado em Matemática pela UCPEL, Especialista em Análise Matemática pela UFPEL, Mestre em Matemática Aplicada e Computacional pela UFSC, Doutor em Educação (Matemática) pela UFPR. Diretor Regional da SBEM-RS gestão 2018-2021. Editor da Revista Vidya. Professor titular aposentado da FURG. Professor do Programa de Pós-Graduação em Ensino de Ciências e Matemática da UFN. Lider do GEPGEO, grupo de ensino e pesquisa em geometria na mesma instituição.

2 Universidade Franciscana, Licenciada em Pedagogia, Mestranda em Ensino de Ciências e Matemática.

${ }^{3}$ Universidade Franciscana, Licenciada em Pedagogia, Mestranda em Ensino de Ciências e Matemática.

4 Programa de Pós-graduação em Ensino de Ciências e Matemática / Universidade Franciscana, Dra. em Educação em Ciências, Docente do Programa de Pós-graduação em Ensino de Ciências e Matemática.
} 
professionals from different areas acting together and the participants creating activities through games that allowed the interlocution of knowledge of the areas involved.

Keywords: Geometrics forms. Herodograms. Pedagogical practices.

\section{INTRODUÇÃO}

A disciplina Ensino de Ciências e Matemática na Infância I, do Programa de Pós-graduação em Ensino de Ciências e Matemática aaaaaaa, é voltada para licenciados em Física, Química, Biologia, Matemática e Pedagogia, os quais se ocupam em aprofundar seus estudos no ensino de Ciências e Matemática desde a Educação Infantil, passando pelo Ensino Fundamental e até o Ensino Médio.

A disciplina em questão oportuniza o estudo e a reflexão entre teoria e prática, visando o letramento científico e matemático desde a infância. Além disso, busca incluir os objetivos do Ensino de Ciências e Matemática nos primeiros anos escolares, dentro dos níveis e possibilidades das escolas, de um modo interdisciplinar.

$\mathrm{Na}$ realidade educacional brasileira, os professores dos anos iniciais, geralmente, são licenciados em Pedagogia e atuam nos primeiros anos escolares como unidocentes, ou seja, necessitam ser e ter conhecimentos polivalentes (PIMENTA et al., 2017) ${ }^{5}$. Assim, eles precisam ter domínio de conteúdos e métodos das Ciências da Natureza, das Linguagens, das Ciências Humanas e da Matemática, além de propor aos estudantes um currículo capaz de prepará-los para as demandas de um mundo globalizado.

$\mathrm{Na}$ Base Nacional Comum Curricular-BNCC (BRASIL, 2017) ${ }^{6}$, o currículo e as recomendações para os primeiros anos escolares das áreas das Ciências da Natureza e da Matemática estão organizados por eixos estruturantes (unidades temáticas), assim como por objetos de conhecimento e habilidades. O estudo da BNCC oportuniza a compreensão da organização curricular, bem como a verificação das competências e habilidades a serem desenvolvidas a partir da mediação dos conhecimentos envolvidos. Além disso, o documento prospecta possíveis articulações interdisciplinares entre as duas áreas do conhecimento, em

\footnotetext{
${ }^{5}$ PIMENTA, S. G.; FUSARI, J. C.; PREDROSO, C. C. A.; PINTO, U. de A. Os cursos de licenciatura em pedagogia: fragilidades na formação inicial do professor polivalente. Educ. Pesqui. vol.43. n.1, 2017. Disponível em: $<$ http://www.scielo.br/scielo.php?script=sci_arttext\&pid=S1517-97022017000100015>. Acesso em: 15 fev. 2018.

${ }^{6}$ BRASIL. Ministério da Educação. Base Nacional Comum Curricular (BNCC). Brasília. Disponível em: http://basenacionalcomum.mec.gov.br/ Acesso em: 12 maio 2019. 
particular o objeto deste estudo.

As propostas de utilização de recursos didáticos para os primeiros anos escolares necessitam se valer de atividades concretas e lúdicas. Geralmente, são utilizados livros didáticos, paradidáticos, histórias infantis, jogos etc. Em se tratando daquelas que visam integrar as áreas em apreço, pode-se partir de um objeto de conhecimento ou de recursos, de modo que as propostas promovam a interlocução de saberes, mesmo daqueles que já estejam sendo utilizados em outras etapas escolares, mas que se adaptem para os anos iniciais.

Segundo os estudos de (v1, 2015, v2, 2016) ${ }^{7}$, o recurso didático utilizado para ensinar hereditariedade na área de Ciências, denominado heredograma, permite a correlação de conhecimentos com a Matemática, uma vez que se vale de símbolos que remetem à geometria. Para os autores, "Um heredograma expressa a estrutura de uma família por várias gerações; representa os indivíduos, as uniões conjugais, a ascendência de um indivíduo, sua descendência ou grupamento familiar" (p.149).

Assim, a representação gráfica de um heredograma faz-se pelo uso de símbolos, linhas e números que se traduzem em informações biológicas dos indivíduos. No entanto, essa mesma representação se alicerça em conhecimentos matemáticos como os da geometria plana. Contudo, se fazem eminentes as interlocuções entre as áreas das Ciências da Natureza $(\mathrm{CN})$ e da Matemática (M), de modo a proporcionar ao professor, que em geral não tem formação nas duas disciplinas, desenvolver, de forma eficaz, os conteúdos de forma interdisciplinar.

Diante do exposto, o presente artigo tem por objetivo analisar possíveis interlocuções entre as áreas do conhecimento $\mathrm{CN}$ e $\mathrm{M}$, a partir do recurso didático heredograma, utilizado em uma atividade interdisciplinar de uma disciplina de um programa de ação continuada, oferecida por um professor de cada uma dessas áreas, concomitantemente, no mesmo espaço de sala de aula.

\section{METODOLOGIA}

O trabalho é de abordagem qualitativa, conforme Prodanov e Freitas (2013, p.70) ${ }^{8}$, os quais indicam: "O ambiente natural é a fonte direta para coleta de dados e o pesquisador é o instrumentochave. Tal pesquisa é descritiva”. A respeito desse tipo de investigação, eles também salientam que

\footnotetext{
${ }^{7} \mathrm{~V} 1$ e V2

${ }^{8}$ PRODANOV, C. C.; ERNANI, C.F. Metodologia do trabalho científico [recurso eletrônico]: métodos e técnicas da pesquisa e do trabalho acadêmico. - 2. ed. - Novo Hamburgo: Feevale, 2013. Disponível em:

<http://www.feevale.br/Comum/midias/8807f05a-14d0-4d5b-b1ad-1538f3aef538/E-

book\%20Metodologia\%20do\%20Trabalho\%20Cientifico.pdf>. Acesso em: 24 ago. 2019.
} 
"Os pesquisadores tendem a analisar seus dados indutivamente. O processo e seu significado são os focos principais de abordagem” (p.70). Para os autores, deve-se explorar tudo que está ao redor dos indivíduos.

O percurso metodológico das aulas da disciplina Ensino de Ciências e Matemática na Infância I foi idealizado a partir de uma sequência de atividades com vistas ao aprofundamento teórico-metodológico das áreas das $\mathrm{CN}$ e da $\mathrm{M}$. As etapas foram extraídas do planejamento dos docentes, pelas duas primeiras autoras do presente artigo, conforme expressas no Quadro 1.

Quadro 1 - etapas das atividades desenvolvidas na disciplina com as respectivas áreas envolvidas.

\begin{tabular}{|c|c|c|c|}
\hline \multirow[t]{2}{*}{ Etapas } & \multirow[t]{2}{*}{ Atividades } & \multicolumn{2}{|c|}{ Áreas } \\
\hline & & EC & $\mathbf{M}$ \\
\hline 1 - Estudo da BNCC & $\begin{array}{l}\text { Eixos estruturantes } \\
\text { Objetos de conhecimentos } \\
\text { Habilidades }\end{array}$ & $\mathrm{X}$ & $\mathrm{X}$ \\
\hline $\begin{array}{l}\text { 2- Aprofundamento teórico } \\
\text { acerca de heredograma e } \\
\text { geometria }\end{array}$ & $\begin{array}{l}\text { Símbolos e decodificação destes. } \\
\text { Interpretação biológica e matemática do heredograma }\end{array}$ & $\mathrm{X}$ & $\mathrm{X}$ \\
\hline 3- Heredograma & $\begin{array}{l}\text { Estudo e técnicas de construção dos próprios e } \\
\text { propostas de atividades com heredogramas e para EI e } \\
\text { Anos iniciais }\end{array}$ & $\mathrm{X}$ & $\mathrm{X}$ \\
\hline 4- Geometria & $\begin{array}{l}\text { Estudo e técnicas de construção das formas } \\
\text { geométricas para EI e Anos Iniciais }\end{array}$ & $\mathrm{X}$ & \\
\hline $\begin{array}{l}\text { 5- Construção de protótipos } \\
\text { de heredogramas }\end{array}$ & $\begin{array}{l}\text { Elaboração dos jogos com a sugestão do heredograma } \\
\text { x formas geométricas }\end{array}$ & $\mathrm{X}$ & $\mathrm{X}$ \\
\hline $\begin{array}{l}\text { 6- Testagem dos protótipos } \\
\text { de heredogramas }\end{array}$ & $\begin{array}{l}\text { Qualificação do material junto aos colegas da turma e } \\
\text { do PPGECIMAT }\end{array}$ & $\mathrm{X}$ & $\mathrm{X}$ \\
\hline $\begin{array}{l}\text { 7- Registros sistematizadores } \\
\text { das atividades. }\end{array}$ & $\begin{array}{l}\text { Foram elaborados, pelas mestrandas, dois jogos: um } \\
\text { quebra cabeça com formas geométricas e o } \\
\text { heredograma; um jogo virtual com as formas } \\
\text { geométricas e o heredograma. Os recursos usados } \\
\text { foram: EVA, tenaz, tesoura, BNCC; artigos; rede } \\
\text { internet; computador; PowerPoint. Artigos usados v1, } \\
\text { 2015. } \\
\text { BNCC; BRASIL, 2017, p.321. } \\
\text { L1;2009, p.136 }\end{array}$ & $\mathrm{X}$ & $\mathrm{X}$ \\
\hline
\end{tabular}


8- Perspectivas Apresentações dos materiais produzidos em eventos como III Espaço Ciência da UFN.

Fonte: os autores

\section{DESENVOLVIMENTO}

Na primeira fase, tomando-se as etapas pautadas pelas disciplinas envolvidas, foi possível realizar um estudo na BNCC, tendo como foco as duas áreas. No documento, encontra-se:

[...] a Matemática cria sistemas abstratos, que organizam e inter-relacionam fenômenos do espaço, do movimento, das formas e dos números, associados ou não a fenômenos do mundo físico. Esses sistemas contêm ideias e objetos que são fundamentais para a compreensão de fenômenos, a construção de representações significativas e argumentações consistentes nos mais variados contextos (BRASIL, 2017, p. 265) ${ }^{9}$.

L1 (2009) ${ }^{10}$ relata que os conceitos estão interligados em diversas áreas do conhecimento matemático e que é necessário trabalhar a prática com suporte teórico para orientar e fundamentar o seu desenvolvimento. $\mathrm{O}$ autor entende

[...] visualização não como uma forma de representação em termos de uma figura ou representação de um objeto e sim como um processo capaz de auxiliar na construção do fazer matemático, bem como na comunicação dos conceitos nas diversas áreas desse conhecimento matemático. (2009, p.136).

Nesse sentido, buscar uma qualidade na formação pedagógica, que consiga interligar a teoria com a prática, encontra guarida na BNCC, a qual pode contribuir na formação didática do professor no seguinte sentido:

\footnotetext{
${ }^{9}$ BRASIL. Ministério da Educação. Base Nacional Comum Curricular (BNCC). Brasília. Disponível em: http://basenacionalcomum.mec.gov.br/ Acesso em: 12 maio 2019.
} 
Aritmética, Álgebra, Geometría, Estatística e Probabilidade, precisa garantir que os alunos relacionem observações empíricas do mundo real a representações (tabelas, figuras e esquemas) e associem essas representações a uma atividade matemática (conceitos e propriedades), fazendo induções e conjecturas (BRASIL, 2017, p.265).

Em se tratando da BNCC (BRASIL, 2017, p.321) para a área das CN, tem-se "[...] um compromisso com o desenvolvimento do letramento científico, que envolve a capacidade de compreender e interpretar o mundo (natural, social e tecnológico) [...]”. Esse documento também sustenta a importância do " [...] acesso à diversidade de conhecimentos científicos produzidos ao longo da história, bem como a aproximação gradativa aos principais processos, práticas e procedimentos da investigação científica”. Essa pluralidade de saberes inclui, evidentemente, a Matemática.

Na segunda etapa da experiência, foi estudado o recurso didático heredograma, isto é, sua estrutura e função, tomando como referência o artigo Genética ${ }^{12}$ na escola. A partir desse referencial, iniciou-se uma busca acerca de quais objetos de conhecimento poderiam ser abordados, tanto na área de $\mathrm{M}$ quanto na área das $\mathrm{CN}$, com base na BNCC, os quais seguem:

Heredogramas x Formas geométricas

Formas geométricas

Quantidade [relações/contagem]

Sistema de numeração

Gráficos

BNCC: Campos de Experiências (Espaços, tempos, quantidades e transformações).

Competência: Matemática, Geometria, Grandeza, Medidas, Comparar, medir e expressar.

No que diz respeito às habilidades, sintetiza-se, no Quadro 2, o que foi detectado na BNCC.

\footnotetext{
${ }^{11}$ BRASIL. Ministério da Educação. Base Nacional Comum Curricular(BNCC). Brasilia. Disponível em: http://basenacionalcomum.mec.gov.br/ Acesso em: 12 maio 2019.

${ }^{12}$ http://media.wix.com/ugd/b703be_1df2d1aff3744486aa38d2f2e67989de.pdf
} 
Quadro 2 - Síntese das habilidades na BNCC

\begin{tabular}{|c|c|c|}
\hline EF01MA09 & $\begin{array}{l}\text { Código indica a nona habilidade } \\
\text { do } 1^{\circ} \text { ano de Matemática. }\end{array}$ & $\begin{array}{l}\text { Organizar e ordenar objetos familiares } \\
\text { ou representações por figuras, por } \\
\text { meio de atributos, tais como cor, } \\
\text { forma e medida. }\end{array}$ \\
\hline EF01MA14 & $\begin{array}{l}\text { Código indica a décima quarta } \\
\text { habilidade do } 1^{\circ} \text { de Matemática }\end{array}$ & $\begin{array}{l}\text { (EF01MA14) Identificar e nomear } \\
\text { figuras planas. }\end{array}$ \\
\hline EF02MA15 & $\begin{array}{l}\text { Código indica a décima quinta } \\
\text { habilidade do } 2^{\circ} \text { de Matemática. }\end{array}$ & $\begin{array}{l}\text { Reconhecer, comparar e nomear } \\
\text { figuras planas. }\end{array}$ \\
\hline EF03MA15 & $\begin{array}{l}\text { Código indica a décima quinta } \\
\text { habilidade do } 3^{\circ} \text { de Matemática. }\end{array}$ & Classificar e comparar figuras planas. \\
\hline EF04MA18 & $\begin{array}{l}\text { Código indica a décima oitava } \\
\text { habilidade do } 4^{\circ} \text { de Matemática. }\end{array}$ & $\begin{array}{l}\text { Reconhecer ângulos retos e não retos } \\
\text { em figuras poligonais com o uso de } \\
\text { dobraduras. }\end{array}$ \\
\hline EF05MA17 & $\begin{array}{l}\text { Código indica a décima sétima } \\
\text { habilidade do } 5^{\circ} \text { de Matemática. }\end{array}$ & $\begin{array}{l}\text { Reconhecer, nomear e comparar } \\
\text { polígonos, considerando lados, } \\
\text { vértices e ângulos. }\end{array}$ \\
\hline
\end{tabular}

Fonte: (BRASIL, 2017, p 277- 295).

A BNCC fornece, ainda, as seguintes competências para as CN - Compreender conceitos e estruturas explicativas; Analisar, compreender e explicar características; Construir com base de dados; Utilizar diferentes linguagens e tecnologias digitais.

$\mathrm{Na}$ terceira etapa do trabalho, houve o aprofundamento teórico acerca da estrutura, função e significados das representações familiares, por meio de heredogramas. Estes são utilizados para expor a ascendência e descendência de um indivíduo, especialmente para localizar, pesquisar e interpretar informações sobre as diferentes espécies (v1, 2015) ${ }^{13}$. Para compor um heredograma, são utilizados ícones (símbolos geométricos) e linhas que seguem convenções internacionais. A Figura 1 expõe os principais símbolos utilizados para se estruturar um heredograma familiar.

Figura 1 - símbolos utilizados em heredogramas 


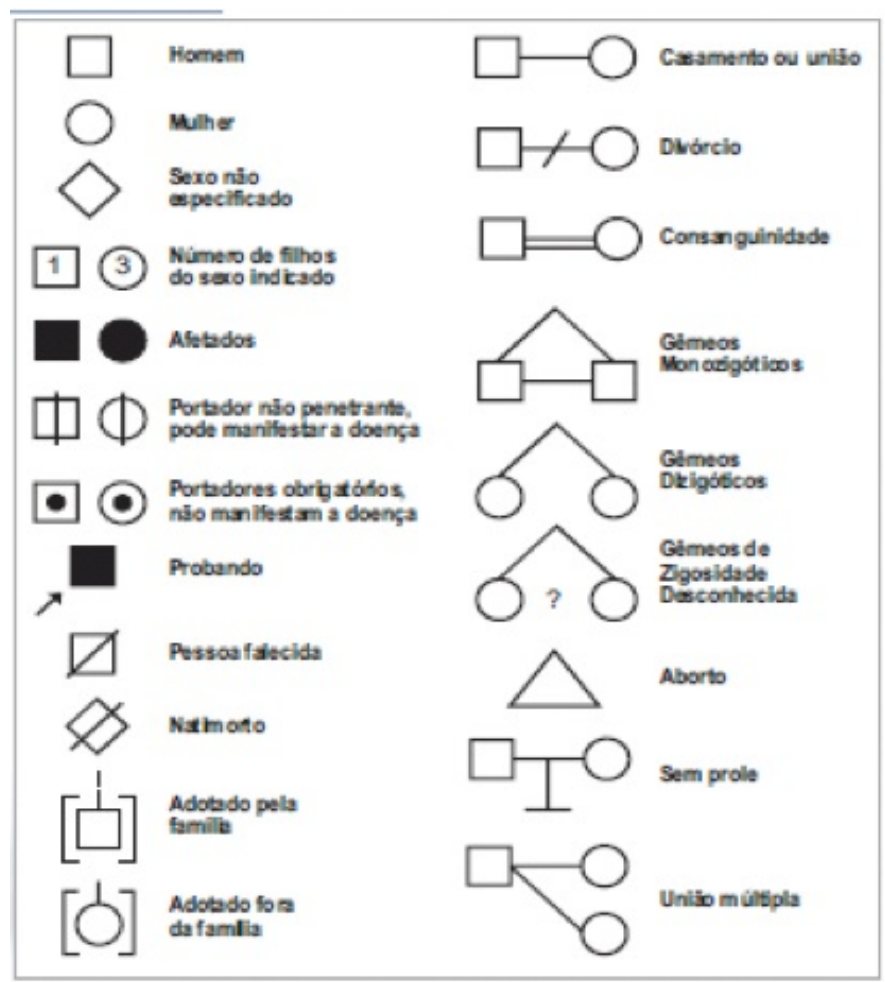

Fonte: v1 (2015, p. 152).

A Figura 1 apresenta a estrutura do heredograma de um indivíduo qualquer. Cada geração encontra-se na linha horizontal, sendo identificada por números romanos (I, II e III). Os indivíduos de cada geração são numerados da esquerda para a direita, por números arábicos, por exemplo, na geração I (1, 2, 3 e 4). Nessa identificação, tornou-se necessário o etudo do sistema de numeração romano por parte da Matemática.

Os indivíduos do sexo feminino são representados por circunferências e os do masculino por quadrados. Os casais (unidos por um traço horizontal) produzem descendentes que representam as gerações seguintes. Por exemplo, a geração I (3 e 4) produziu uma prole constituída pelos indivíduos pertencentes a geração II (2, 3 e 4). Percebe-se, aqui, a necessidade de realizar estudos sobre figuras geométricas planas, bem como algumas relações como segmentos de reta, horizontalidade e verticalidade, perpendicularismo e paralelismo, dentre outros conceitos geométricos.

Figura 2 - estrutura de um heredograma, cujo indivíduo em análise é III (2) 


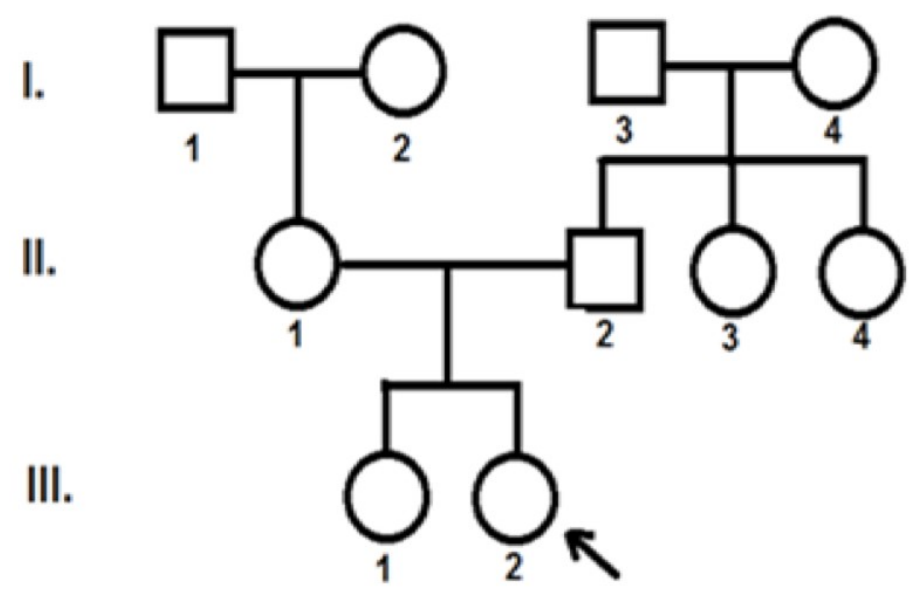

Fonte: v1 (2015). ${ }^{14}$

$\mathrm{Na}$ quarta etapa, houve o estudo das formas geométricas envolvidas nos heredogramas. Relata-se, aqui, maneiras alternativas de construção das formas geométricas que são envolvidas nos heredogramas, como quadrados e regiões quadradas, triângulos e regiões triangulares, retângulos e regiões retangulares, circunferências e círculos.

Para realizar atividades interdisciplinares, o professor de Matemática discutiu como explorar os conceitos geométricos envolvidos no heredrograma, como também poderiam ser feitas atividades com alunos dos Anos Iniciais, explorando o recurso didático papel. Inicialmente, forneceu aos estudantes uma folha em um formato qualquer, a qual não possui forma geométrica definida, a exemplo do que é feito com material reciclado. A partir dela, propôs deixá-la no formato retangular, explorando o material e os elementos geométricos envolvidos.

Os participantes foram convidados a realizar dobras específicas na folha, seguindo orientações do professor. Após as primeiras dificuldades com a linguagem geométrica, os estudantes estipularam nomenclaturas adequadas aos entes geométricos citados que estavam sendo representados. Os questionamentos e os diálogos da turma, que se desenvolveram de forma espontânea e prazerosa, foram propiciando um espaço de construção de conhecimento de relevância para a comunidade de educadores dos Anos Iniciais participantes da turma (todos com formação em Pedagogia). Estes, geralmente, por não gostarem de Matemática, até certo ponto, rejeitavam sua aprendizagem. 
Manifestações a posteriori desses professores indicaram a crença de que, dessa forma, as salas de aula se tornam mais prazerosas e interessantes por envolver os alunos no processo.

Algumas formas geométricas usadas para representações no heredograma (Figura 1) passaram a ser observadas do ponto de vista geométrico, inclusive com a constatação de propriedades básicas destas. São elas:

- o quadrado ou região quadrada representa pessoa do sexo masculino;

- a circunferência ou círculo representa pessoa do sexo feminino.

- o triângulo ou região triangular representa um aborto.

A discussão, nesse momento, foi a respeito de outros símbolos associados a essas formas, como, por exemplo, representar apenas as linhas de contorno [quadrado, circunferência, triângulo] ou, por outro lado, pintar os interiores de preto (correspondem: região quadrada, círculo, região triangular). Ainda, outras representações com linhas, pontos etc emergiram. Isso proporcionou aprendizagem de conceitos geométricos que, nem sempre, são distinguidos, como no caso da circunferência e do círculo, por exemplo. Ao primeiro está associada a grandeza comprimento, enquanto, ao segundo, a grandeza área.

Portanto, aqui se apresenta uma conexão que os participantes gostaram de realizar, explorando a visualização, no sentido apontado por L1 (2009). ${ }^{15}$, de objetos concretos do heredograma com construtos mentais da geometria plana. Por sua vez, ao discutir o quadrado como a representação do masculino e a circunferência do feminino, fica estabelecida a requerida conexão interdisciplinar. O mais importante é que $\mathrm{CN}$ e $\mathrm{M}$ podem ser trabalhadas interdisciplinarmente e, nas escolas, abordadas em conjunto, inclusive agregando outros temas.

Retomamos a construção geométrica do masculino, partindo da tal folha sem formato definido, o papel irregular (Figura 3).

Figura 3 - Folha irregular com a representação de uma reta

${ }^{15} \mathrm{~L} 1$ 


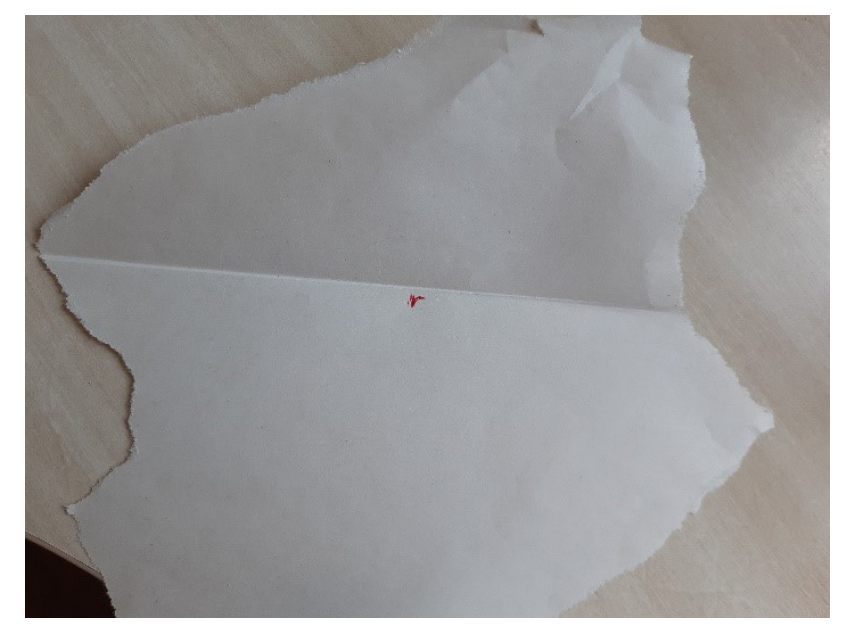

Fonte: os autores

Para obter a forma retangular, foram explorados conceitos geométricos como o de reta ou o de segmento de reta, visualizados a partir da linha de dobra ' $r$ ' da folha. (Figura 3). Assim, para obter uma reta nessa folha de papel, sem forma definida, deve-se simplesmente dobrá-la, ou refletir a folha sobre si mesma e vincá-la bem. Aqui, já tornou-se possível explorar, intuitivamente, o conceito de reflexão. Isso ocorre, pois a linha de dobra pode ser pensada, geometricamente, como a intersecção dos dois planos (as partes da folha irregular). Na realidade, seria um segmento de reta por estar limitada entre as duas bordas da folha, ou seja, pontos A (à esquerda) e B (à direita), (Figura 4). Entretanto, não se perde a generalidade, pois considera-se o plano representado pela folha, com suas fronteiras. Explora-se, também, o significado de semirreta, semiplano e a limitação da representação de um plano geométrico (construto mental abstrato) por meio da folha.

Figura 4 - reta r ou segmento de reta AB.

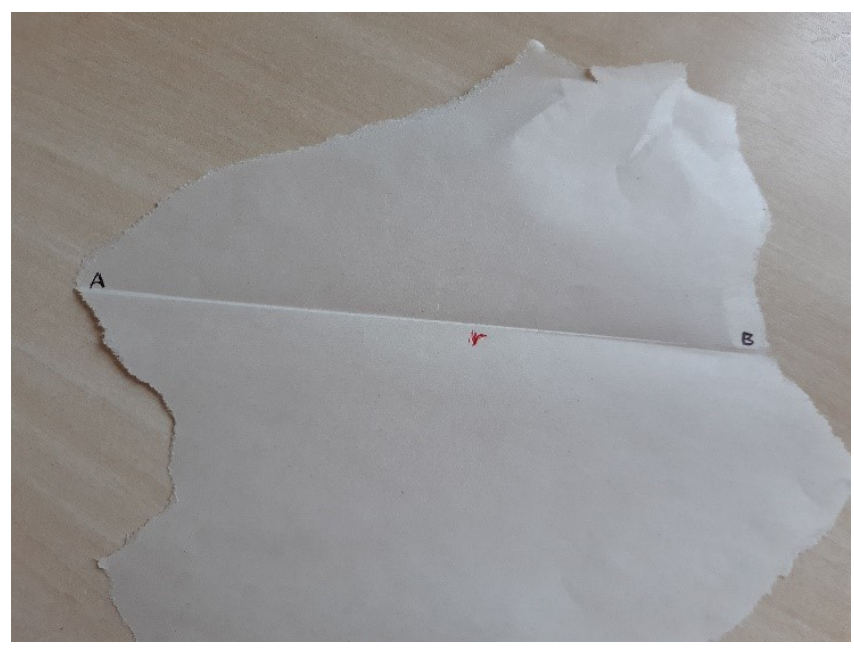

Fonte: os autores 
Ao dobrar a folha novamente, agora tomando um ponto qualquer $\mathrm{C}$ da linha de dobra entre A e B, e fazendo refletir a 'reta r' sobre si mesma, se formam duas semirretas de mesma origem C, isto é, aquele ponto onde foi feita a reflexão torna-se a origem das duas semirretas. Também, ao desdobrar a reflexão da reta em torno do ponto $C$, verifica-se que apareceu uma segunda linha tendo apenas aquele ponto em comum e, consequentemente, obtém-se o ângulo reto $\left(90^{\circ}\right)$, ou seja, duas retas perpendiculares. Assim, ficam visualizadas quatro semi retas com uma origem comum C, conforme a Figura 5.

Figura 5 - ângulo reto por dobradura e linhas perpendiculares.

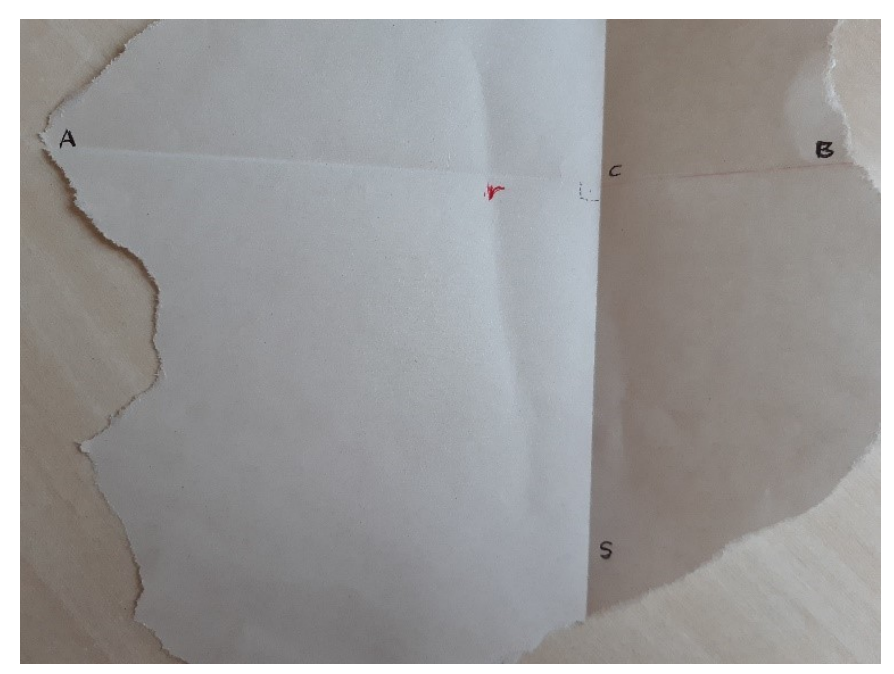

Fonte: os autores

Com a folha aberta ou desdobrada, toma-se a segunda linha obtida (semirreta) e repete-se a última ação por um ponto D qualquer. Ao desdobrar-se, surge um segundo ângulo reto no ponto D. Quando se repete o processo para a terceira semirreta, em qualquer ponto E, vai produzir o terceiro ângulo reto e, automaticamente, o quarto ângulo (os quatro lados da região retangular CDEF).

Figura 6 - formação dos quatro ângulos retos. 


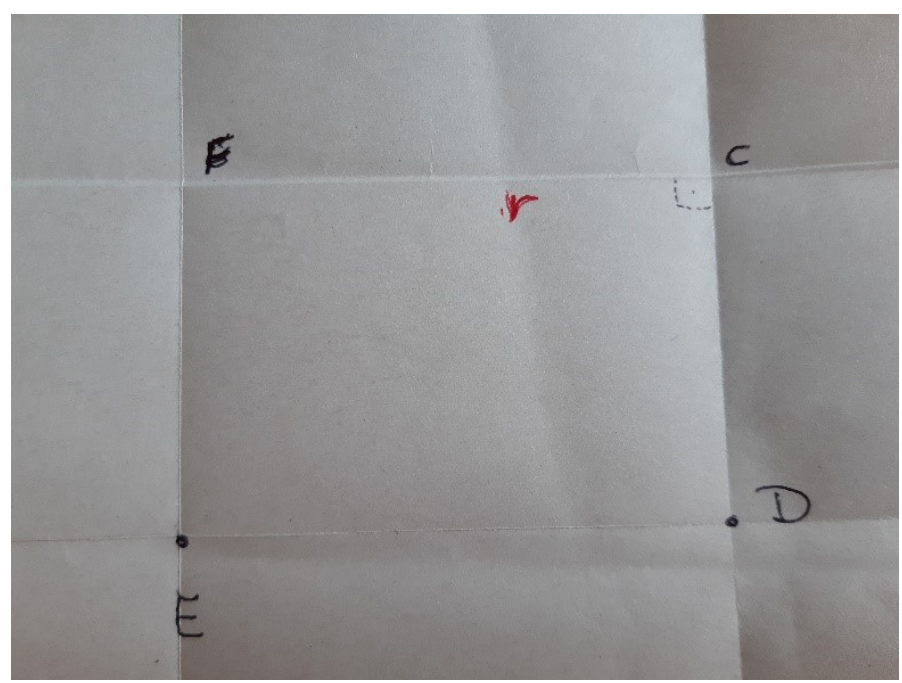

Fonte: os autores

Dessa forma, é possível obter uma região retangular a partir de uma folha irregular qualquer e explorar conceitos emergentes da geometria para os Anos Iniciais do Ensino Fundamental, sem o formalismo de definições prévias e abstratas, como é comum ocorrer nos espaços escolares e livros didáticos. As quatro dobras consecutivas fornecem a região retangular obtida por dobraduras, inclusive com a obtenção dos ângulos retos. Observando os lados opostos e suas medidas, é possível concluir que apresentam essas mesmas medidas, caracterizando quadriláteros com lados paralelos dois a dois e congruentes. Em particular, esses são denominados paralelogramos retângulos por possuírem os quatro ângulos retos.

No que segue, ilustra-se como os participantes da atividade obtiveram a forma do quadrado a partir da retangular. Considera-se que a folha irregular está no formato retangular, como no processo analisado antes, isto é, CDEF. Deseja-se, agora, torná-la no formato quadrangular. Para tal, deve-se transportar o lado de menor medida, a saber, CD, para o de maior, ou seja, FC. Para isso, é necessário determinar um ponto $\mathrm{M}$ sobre o maior FC, fazendo-se uma rotação do lado CD em torno do ponto D até fazer D encontrar o lado FC, obtendo-se o ponto M. Assim, CD tem a mesma medida de MC. Basta fazer uma reflexão do lado FC sobre si mesmo pelo ponto M, cuja linha de dobra, perpendicular a MC e paralela a CD, determinará o ponto $\mathrm{N}$ sobre o lado oposto a MC (Figura 7).

Figura 7 - obtenção do quadrado. 

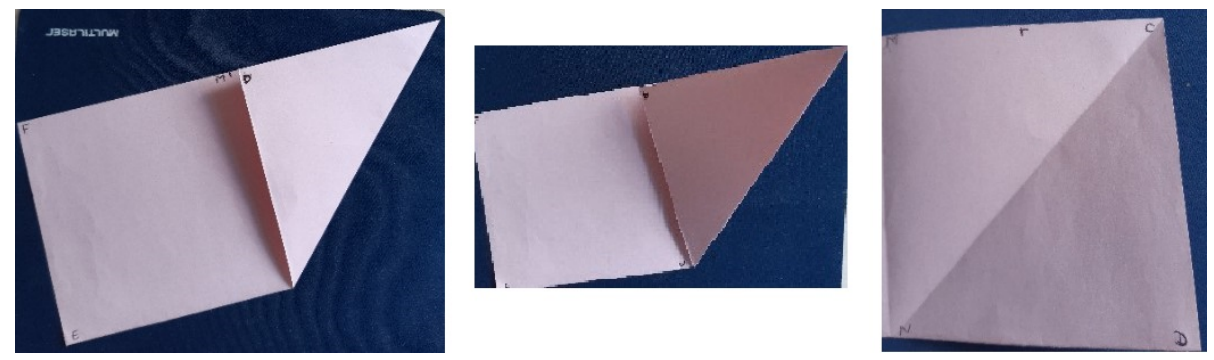

Fonte: os autores

Portanto, CDNM é formado por quatro lados de mesma medida e dois a dois formando ângulos retos, o que caracteriza a figura obtida pelas linhas de dobra como um quadrado.

Na quinta etapa, foi sugerida a construção de protótipos de heredogramas e a elaboração de jogos, com a intenção de interligar as formas geométricas com o heredograma. Na sequência, apresenta-se os dois jogos criados pelas duas estudantes.

\section{JOGO VIRTUAL COM AS FORMAS GEOMÉTRICAS E O HEREDOGRAMA}

Este primeiro jogo foi criado por uma das autoras do artigo YYYY, a qual buscou associar e exercitar o uso das formas geométricas como símbolos do heredograma em diferentes tipos de linguagem. Com isso, há interligação do ensino de $\mathrm{M}$ com o de $\mathrm{CN}$, de maneira lúdica (Figura 8) . O jogo foi elaborado para ser explorado apenas virtualmente.

Figura 8 - Jogo descobrindo as formas geométricas e símbolos do heredograma.

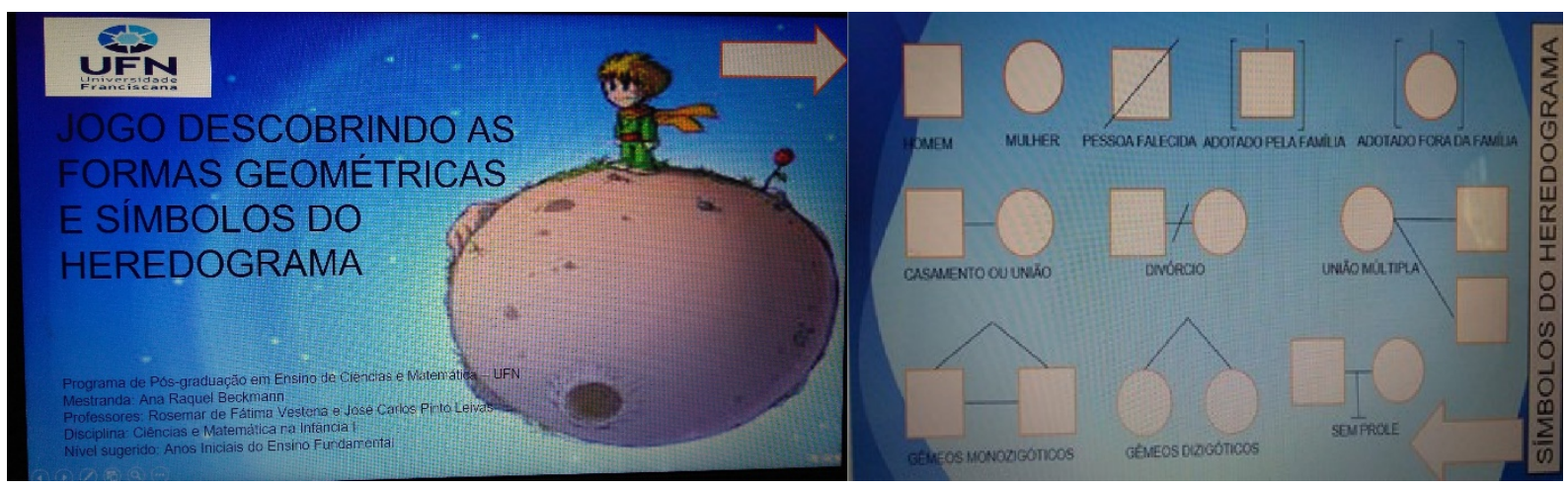




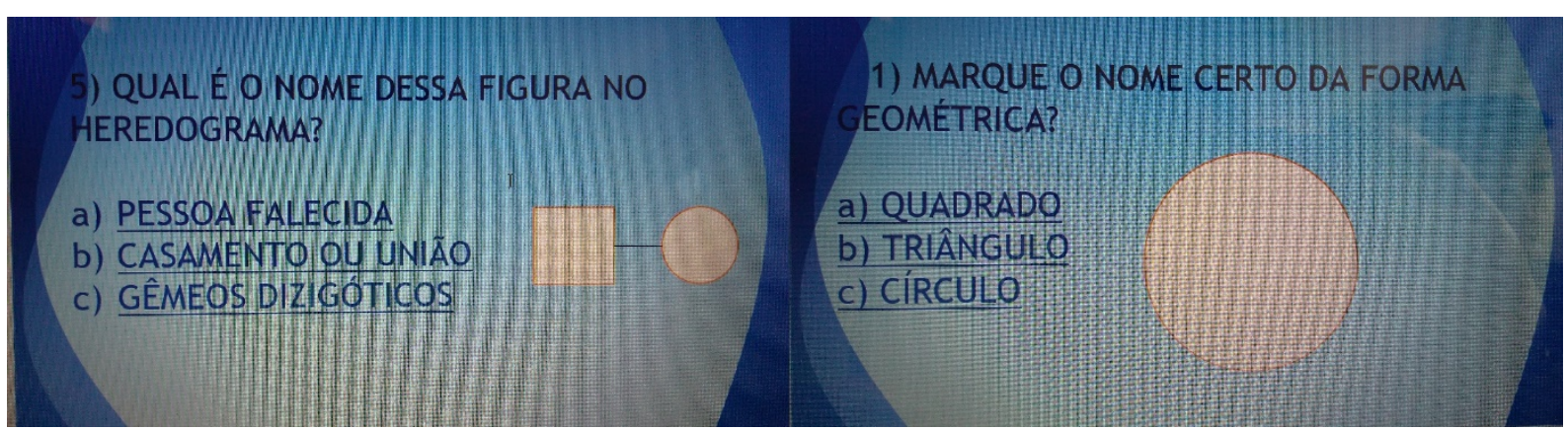

Fonte: YYYY.

No Quadro 3, apresenta-se as regras de funcionamento do Jogo Virtual com as Formas Geométricas e o Heredograma.

Quadro 3 - o jogo e sua forma de jogar 


\begin{tabular}{|l|l|}
\hline MATERIAIS & $\begin{array}{l}\text { BNCC; } \\
\text { Artigos; } \\
\text { Rede internet; } \\
\text { Computador; } \\
\text { PowerPoint. }\end{array}$ \\
\hline OBJETIVO GERAL & $\begin{array}{l}\text { Trabalhar e exercitar o uso das formas geométricas como símbolos do } \\
\text { heredograma com diferentes tipos de linguagem. }\end{array}$ \\
\hline EBJETIVOSIFICOS & $\begin{array}{l}\text { Identificar os nomes das figuras; } \\
\text { Relacionar o nome as figuras; } \\
\text { Relacionar as forma e símbolos; } \\
\text { Socializar os alunos para trabalhar em grupos; } \\
\text { Integrar os elementos dos grupos; } \\
\text { Mostrar, por meio de formas geométricas, o heredograma; } \\
\text { Desenvolver estratégias para a aprendizagem do heredograma. }\end{array}$ \\
\hline CONTEÚDOS & $\begin{array}{l}\text { Formas geométricas planas; } \\
\text { Quantidade [relações/contagem]; } \\
\text { Sistema de numeração; } \\
\text { Gráficos. }\end{array}$ \\
\hline FORMAS DE AVALIAR & $\begin{array}{l}\text { O aluno deve identificar as formas geométricas que estão relacionadas com } \\
\text { o heredograma. }\end{array}$ \\
\hline FOnte: & $\begin{array}{l}\text { O aluno dá um clic com o mouse em cima da seta indicadora para poder } \\
\text { jogar e responder as perguntas. }\end{array}$ \\
\hline
\end{tabular}

Fonte: elaborado pela autora do jogo.

O segundo jogo foi elaborado pela estudante XXX, conforme apresenta-se a seguir.

\section{QUEBRA-CABEÇAS NA CIÊNCIA E NA MATEMÁTICA: QUEM SOU?}

Este segundo jogo (Figura 9) envolve o heredrograma nas Ciências e formas geométricas na Matemática e foi desenvolvido para ser explorado na Educação Infantil. A proposta busca auxiliar o processo de formação educacional e cognitiva de uma criança, valorizando a importância do conhecimento. Foi idealizado pela segunda autora do artigo XXX, professora da Educação Infantil e aluna da disciplina em questão.

Figura 9 - Quebra-cabeças na Ciência e na Matemática: quem sou? 


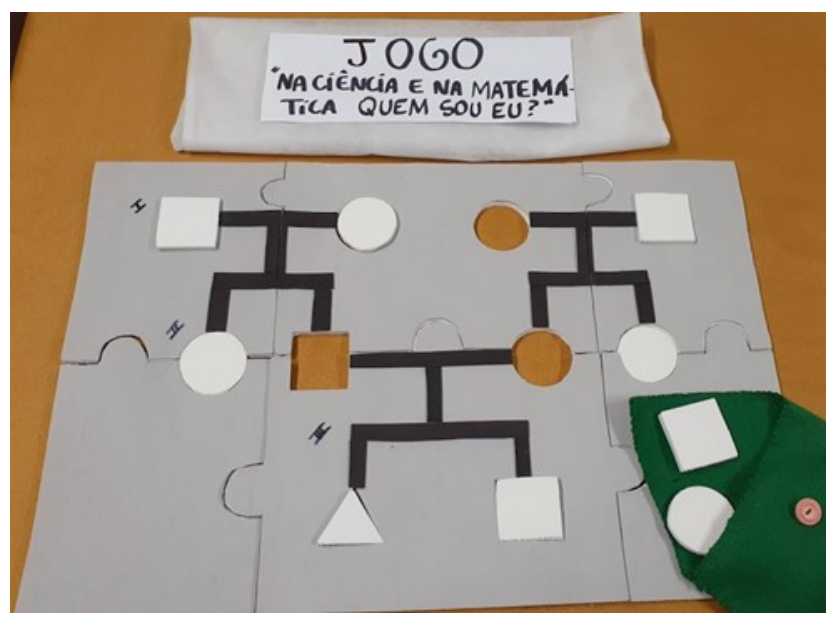

Fonte: XXXX.

No Quadro 4, apresenta-se as regras de funcionamento do jogo Quebra-cabeças na Ciência e na Matemática: Quem Sou?

Quadro 4 - o jogo e sua forma de jogar 


\begin{tabular}{|c|c|}
\hline MATERIAIS & $\begin{array}{l}\text { BNCC; } \\
\text { Artigos; } \\
\text { EVA; } \\
\text { Tesoura; } \\
\text { Tenaz; } \\
\text { Feltro; } \\
\text { TNT. }\end{array}$ \\
\hline OBJETIVO GERAL & $\begin{array}{l}\text { Fazer cada criança compreender que através do jogo de um } \\
\text { heredograma podem ser abordados conteúdos das duas disciplinas: } \\
\text { Ciências e Matemática. }\end{array}$ \\
\hline OBJETIVOS ESPECÍFICOS & $\begin{array}{l}\text { Identificar os nomes das figuras geométricas planas; } \\
\text { Relacionar as formas aos símbolos; } \\
\text { Diferenciar as formas geométricas do heredograma; } \\
\text { Trabalhar em grupo; } \\
\text { Desenvolver a atenção e o raciocínio lógico. }\end{array}$ \\
\hline CONTEÚDOS & $\begin{array}{l}\text { Matemática (Formas geométricas, quantidade e gráfico); } \\
\text { Ciências (genética de cada indivíduo); } \\
\text { Português (nomes, vogais e consoantes). }\end{array}$ \\
\hline FORMAS DE AVALIAR & $\begin{array}{l}\text { A avaliação será de acordo com o desempenho de cada criança e } \\
\text { levará em consideração o objetivo da aprendizagem. }\end{array}$ \\
\hline COMO JOGAR & $\begin{array}{l}\text { Primeiramente, a criança terá de montar o quebra cabeça e, logo após, } \\
\text { encaixar o restante das peças no lugar, conforme o heredograma. }\end{array}$ \\
\hline
\end{tabular}

Fonte: elaborado pela autora do jogo.

$\mathrm{Na}$ sexta etapa, realizou-se a pilotagem dos jogos sobre os heredogramas e as formas geométricas, construídos pelas duas alunas e aplicados com os demais colegas de turma. Assim, nessa etapa, aconteceu a qualificação do material e sua validação pelo grupo, surgindo algumas possibilidades de melhorias, as quais foram incorporadas aos protótipos para alcançar os objetivos almejados.

$\mathrm{Na}$ sétima etapa, foram feitos os registros que sistematizaram as atividades com os dois jogos. Retomaram-se os recursos utilizados, conforme os Quadros 3 e 4.

\section{CONSIDERAÇÕES FINAIS}

O presente artigo visou analisar as interlocuções entre a área das $\mathrm{CN}$ e a da $\mathrm{M}$ e ilustrou que é possível interligar conteúdos de disciplinas de ensino de Ciências e de Matemática na Infância, especialmente voltadas para licenciados em Pedagogia. Buscou-se ampliar estudos e experiências no ensino das duas áreas do conhecimento, atendendo a demanda de maior qualificação frente aos 
saberes específicos, com vistas ao ensino globalizado e assumido, geralmente, pela unidocência nessa etapa escolar.

A disciplina oportunizou estudos e reflexões dos assuntos, especialmente nas áreas da $\mathrm{M} \mathrm{e}$ das $\mathrm{CN}$, aliando teoria e prática, com vistas ao letramento científico e matemático para a infância. Incluiu, também, os objetivos do Ensino de Ciências e de Matemática nos primeiros anos escolares, dentro dos níveis e possibilidades das escolas, de modo interdisciplinar, atendendo às demandas da BNCC.

Contudo, o uso de recursos didáticos como o heredograma se alinhou aos objetos de conhecimentos das áreas $\mathrm{CN}$ e $\mathrm{M}$, uma vez que tem potencial de abordar conhecimentos sobre a vida, a evolução (hereditariedade e reprodução sexuada) e a geometria. Outrossim, esse recurso pode inspirar outras atividades e modelos de jogos, adaptando-se a faixa etária das crianças nas escolas.

Os resultados mostraram ser viável implementar uma disciplina de forma interdisciplinar, envolvendo dois profissionais de áreas distintas atuando conjuntamente, além de participantes que criaram atividades por meio de jogos que possibilitaram a interlocução de saberes das áreas das CN e da M. Os demais componentes do grupo também tiveram a oportunidade de avaliar criticamente e de validar a construção dos recursos didáticos. Além disso, esses outros professores em ação continuada também elaboraram suas aplicações, o que constará de nova produção científica.

\section{REFERÊNCIAS}

BRASIL. Ministério da Educação. Base Nacional Comum Curricular(BNCC). Brasília. Disponível em: http://basenacionalcomum.mec.gov.br/ Acesso em: 12 maio 2019.

PIMENTA, S. G.; FUSARI, J. C.; PREDROSO, C. C. A.; PINTO, U. de A. Os cursos de licenciatura em pedagogia: fragilidades na formação inicial do professor polivalente. Educ. Pesqui. vol.43. n.1, 2017. Disponível em: <http://www.scielo.br/scielo.php?script=sci_arttext\&pid=S1517-97022017000100015>. Acesso em: 15 fev. 2018. 
PRODANOV, C. C.; ERNANI, C.F.;. Metodologia do trabalho científico [recurso eletrônico]: métodos e técnicas da pesquisa e do trabalho acadêmico. - 2. ed. - Novo Hamburgo: Feevale, 2013. Disponível em: <http://www.feevale.br/Comum/midias/8807f05a-14d0-4d5b-b1ad1538f3aef538/E-book\%20Metodologia\%20do\%20Trabalho\%20Cientifico.pdf $>$. Acesso em: 24 agos 2019 . 